\title{
A Systematic Literature Review of the Current State of Knowledge Related to Interventions for Bereaved Parents
}

\author{
Nancy Dias, Verna L. Hendricks-Ferguson, Holly Wei, Elizabeth Boring, Kerry Sewell, Joan E. Haase
}

\section{Introduction}

Bereavement following the death of a child is one of the most excruciating life experiences for parents. ${ }^{1}$ More difficult than any other bereavement, coping with the grief after a child's death can change parents' lives and pose significant negative impact on their health. ${ }^{2}$ Bereaved parents are extremely susceptible to experiencing distress related to their well-being (i.e., physical, mental, emotional, quality of life) and have increased mortality risks.,

In 2016, according to the World Health Organization's statistics report, approximately 15,000 children under-five years of age and 3,000 children between the ages of 5 and 14 years, died every day worldwide. ${ }^{5}$ In the United States, about 40,000 infants and children die annually and more than 400,000 children live with life-threatening or chronic, complex conditions. ${ }^{6}$ Bereavement affects all members of the immediate family, with parents and siblings exhibiting significant health issues, ${ }^{7-9}$ which could pose a significant risk to population health.

Bereaved parents often experience intense and lasting psychological distress and post-traumatic stress-related symptoms, including anxiety and depression. Following a child's death, the first six months are physically the most difficult for bereaved parents; they experience increased acute illnesses, hospitalizations, and medication changes. ${ }^{10}$ Bereaved parents are prone to illnesses and related health concerns; $25 \%$ of the bereaved parents reported new diagnoses of illnesses including prediabetes, anxiety, and sleep disorder. ${ }^{11}$ Bereaved parents also experience psychological distress such as anxiety, posttraumatic stress disorder, and grief-related depressive symptoms that continue to be significant for years after a child's death. ${ }^{8,12,13}$

In addition to the physical health of parents, the death of a child can affect social relationships. Bereaved parents report decreased communication, feelings of isolation, an absence of close social

This is the author's manuscript of the article published in final edited form as:

Dias, N., Hendricks-Ferguson, V. L., Wei, H., Boring, E., Sewell, K., \& Haase, J. E. (2019). A Systematic Literature Review of the Current State of Knowledge Related to Interventions for Bereaved Parents. American Journal of Hospice and Palliative Medicine, 36(12), 11241133. https://doi.org/10.1177/1049909119858931 
relationships, and increased marital strain and divorce. ${ }^{14,15}$ When not adequately addressed, psychological symptoms of bereaved parents can lead to chronic illnesses and negative interpersonal relationships. ${ }^{4}$

Providing effective support to bereaved parents requires an understanding of existing bereavement-support interventions. In order to move the science forward, the promotion of evidencebased interventions for parents requires an evaluation of existing bereavement interventions including the use of theoretical models or frameworks, measures, and study designs. We initially conducted a review to evaluate the existing evidence about parental bereavement-care interventions and found literature reviews of: hospital-based bereavement service interventions, ${ }^{16,17}$ neonatal intensive care unit based bereavement service interventions, ${ }^{18}$ randomized-controlled trials of bereavement interventions, ${ }^{19,20}$ measures used in bereavement care intervention studies, ${ }^{17}$ and parents' expectations from healthcare professionals after the sudden death of their child. ${ }^{21}$ Forte et al. ${ }^{22}$ conducted a literature review that was wider in scope to include all bereaved individuals and specific to interventions directed to address the grief response to bereavement.

While Endo et al. ${ }^{19}$ conducted a review that assessed interventions for bereaved parents, it only included randomized control trials. Considering the paucity of research in this field, our review included all types of studies that tested bereavement care interventions for bereaved parents of children who died of acute or chronic illness. Therefore, the purpose of this literature review is to describe interventions for bereaved parents of children and assess the effectiveness of these interventions by evaluating the quality of the intervention and quality of the research, including methods, measures, and theories used.

\section{Methods}

An experienced librarian (Co-author KS) searched MEDLINE via PubMed (1966-2018), CINAHL (1937-present), PsycINFO (1887-present), and Embase (1947-present) to identify published research studies describing bereavement care interventions for bereaved parents. See Figure 1 for the PRISMA flow chart. The librarian iteratively developed keywords related to the domains of parents, children, bereavement, and a select set of terms to capture interventional research. The keywords were combined with controlled vocabulary from PubMed/MEDLINE (Supplementary Table 1) for the purpose 
of preliminary search testing and construction. The librarian then mapped and implemented the search strategy across the databases identified. The last database search was conducted on November 8, 2017. Only English language publications were included, but no date limit was applied.

\section{Study Selection}

Records were de-duplicated using software (Rayyan:http://rayyan.qcri.org) and then, subsequent manual deduplication. After de-duplication of records, one author (ND) and one research assistant screened titles and abstracts for inclusion in this review paper. We included fully published empirical studies (i.e., qualitative, quantitative, mixed methods, case studies, case reports) that examined any intervention for bereaved parents after their child's death from acute or chronic illness. Due to the paucity of the literature and the heterogeneity of the samples, we retained studies if the sample included children who died of any cause including accidental deaths as part of their sample. We excluded parent bereavement studies specifically focused on: (a) traumatic deaths of children, including suicide and homicide, (b) interventions for family members outside of the parental role, such as grandparents and siblings, (c) studies that evaluated bereavement care program, and (d) reviews, editorials, and conference abstracts. A search of references was also conducted.

\section{Data Extraction and Quality Assessment}

After reviewing the titles and abstracts, 63 records were retained. The selected records were divided equally among four of the manuscript authors for full-text initial review. Based on this review, 54 records were eliminated because they did not meet our literature review inclusion and exclusion criteria. Three of the nine records retained for full review were dissertation studies but had tested bereavement interventions. The Grading of Recommendations Assessment, Development, and Evaluation (GRADE) tool $^{23,24}$ was used to rate any identified methodological flaws, inconsistencies, and effect sizes of the reviewed research articles.

The GRADE criteria were designed to rate the quality of evidence of published research studies using a systematic approach (i.e., high, moderate, low and very low). For example, the determination of a strong GRADE rating includes studies that provide strong evidence that further research is very unlikely 
to change our confidence in the reported results. In comparison, the determination of a very low GRADE rating includes studies in which any estimate of effect is very uncertain (e.g., descriptive studies without any type of randomization procedures). Our research team members entered review criteria on the GRADE matrix tables for each of the nine retained studies.

The GRADE matrix tables summarized key elements of the articles including purpose; design and variables; study participants; measures; intervention details (i.e., type, time, personnel); theory; results; and implications. Any disputes regarding article selection were settled during our research team meetings by describing the study and subsequent discussions were based on our review of the inclusion and exclusion criteria. The GRADE Matrix Tables for all nine studies were developed and discussed during our research team meetings. During scheduled conference calls, the research team provided a verbal review and critique of each assigned study and accuracy of the matrix table. The team then determined a GRADE criteria level of evidence (overall rating) for the quality of the body of evidence for each study and recommendations (e.g., strong to very low) were based on the GRADE criteria guidelines $\left(\right.$ see Table 1). ${ }^{24}$

\section{Results}

Results of this research include the review of interventions for bereaved parents reported in nine articles (Table 2). The results section is discussed based on the: (a) types of parent bereavement interventions; (b) intervention effectiveness; (c) theoretical frameworks used to guide the interventions; (d) timing of interventions; and (f) recruitment and sample size.

\section{A. Types of Parent Bereavement Interventions}

The types of parent bereavement interventions were classified according to the modes of the interventions (i.e. single-modal or multi-modal interventions) and the study design and content. Six studies were single-modal interventions ${ }^{25-30}$ and three were multi-modal interventions. ${ }^{31-33}$

\section{Single-modal interventions}




\section{Support-groups.}

Heiney et al. ${ }^{25}$ evaluated a parent support group intervention delivered in eight bi-weekly, one-hour group sessions to one group of five parents and led by two healthcare professionals (i.e., a psychologist and a nurse practitioner). The five parents included two parent dyads and one single parent whose children had died of cancer within the last 2 to 26 months. The study used a single-group pre-test/post-test design that evaluated parents' outcomes using qualitative and quantitative methods. The first intervention session began with group discussions about group rules (e.g., empathetic listening and maintaining confidentiality about individual discussions during all group sessions). Topics discussed during the six sessions included memories of the child's illness, death and funeral, family reactions, the meaning of the loss, and parents' feelings about the loss and their future. Outcomes evaluated included psychosocial function, including emotional status, and family and social adjustment. The investigators reported no statistically significant findings and attributed the results to the small sample size (i.e., five parents).

\section{Psycho-therapy/cognitive-focused Interventions.}

Three studies described psychotherapy interventions: (a) group therapy retreat, (b) mindfulness-based counseling, and (c) cognitive-behavioral therapy.

Group therapy. Brown $^{29}$ as a dissertation work used a quasi-experimental with a nonequivalent-control group design with bereaved parents whose child had died within the past five years. Ages of the deceased children were not reported but stated that the organization offers services to parents of children of all ages including stillbirth. Bereaved parents in the intervention group attended a 48-hour weekend retreat, which consisted of 4 formal group-therapy sessions facilitated by either a psychologist or a social worker. ${ }^{29}$ The parents who chose to attend the weekend retreat sponsored by an organization were part of the intervention group. The control group consisted of parents who were invited for the retreat but did not attend the weekend retreat. The intervention provided opportunities for bereaved parents to form support networks as they interacted with other participating bereaved parents during each session. The study design was 
within and between subjects' analyses. The sample included 84 bereaved parents (i.e., 38 fathers and 46 mothers). Parents in both groups completed data collection at baseline (pre-test) prior to the retreat and after the last session (post-test) using measures of perceived social support, depression, and general well-being. Parents who participated in the retreat showed: a significant decrease in depressive symptoms, significant improvement in perceived quality of life, and no change in perceived social support. In contrast, the responses of parents in the control group did not show a significant change in depressive symptoms, perceived quality of life, or perceived social support.

Mindfulness-based intervention. Cacciatore et al. ${ }^{30}$ described the use of a mindfulnessbased bereavement focused intervention as a case study. The intervention was delivered by a social worker to a 34-year-old African American single father whose 13-year old son died unexpectedly due to a cardiac condition. ${ }^{30}$ This intervention is based on the ATTEND (attunement, trust, therapeutic touch, egalitarianism, nuance, and death education) model. ${ }^{30}$ The ATTEND model encompasses a focus on self-care of the bereaved individual and the facilitator conveying compassion to the bereaved individual. ${ }^{30}$ The ATTEND model is also described as tripartite in that the client, the relationship, and the clinician experience and benefit from the elements during the implementation of the model. In this case study, the father completed measures to assess perceived anxiety and depression using the Hopkins Symptoms Checklist-25 (HSCL-25) and emotional trauma using the Impact of Event Scale-Revised (IES-R) at three-time points over 20 months (i.e., at baseline, between three to four months, and after 20 months). ${ }^{30}$ The father's responses on both study measures showed a decrease in symptoms over time but remained above the "threshold for psychopathology." However, the parent was also on psychotropic medications for an unspecified portion of the mindfulness-based treatment timeframe and the effect of these medications on the father's improved state was unclear.

Cognitive-behavioral therapy. Dawson' ${ }^{28}$ dissertation work conducted a nonequivalentcomparison group study in which 10 bereaved parents who had lost a child, aged between 4 and 
20 years and within the last 3 years, participated. Parents were assigned to the intervention group if they were willing to participate in the five to six therapy sessions. Six parents were assigned to the intervention group. Parents in the intervention group attended -five to six cognitive-behavioral therapy group sessions, over six weeks. The duration of each intervention group session was from one-and-a-half to six hours. Intervention sessions included topics about grief, coping, stress management, relaxation exercises, developing memories and family rituals. Four parents were assigned to the control group. Parents in the control group received a mailed grief-support book titled: Tear Soup: A Recipe for Healing After Loss. All enrolled parents completed the same measures (i.e., Beck Depression Inventory, State/Trait Anxiety Inventory, Symptom Checklist 90-Revised, and the Group Cohesiveness Scale). Results showed the intervention group had a significant reduction in overall grief symptoms (e.g., anger, guilt, despair, \& sadness) compared to the parents' responses in the control group. Parents with more time elapsed since their child's death had a greater decrease in symptoms. However, there was no statistical difference in pre-test and post-test scores of the intervention group on any of the standardized measures listed above. Additionally, the effect of confounding variables on study outcomes was not addressed, though the author stated that non-randomization and the non-equivalent comparison group design posed threats to the internal validity of the study.

\section{Intentional touch.}

Kempson $^{26}$ described a quasi-experimental non-equivalent pre-test/post-test controlgroup design to evaluate the effect of therapeutic intentional touch therapy (i.e., the Tragers' Psychophysical Integration) on bereaved mothers' grief (Grief Experience Inventory) and perceived social support (Multi-dimensional Scale of Perceived Social Support). Enrolled mothers were randomized to either the intervention group $(n=31)$ or the control group $(n=34)$. The intervention group included parents who received the intentional touch therapy. Parents who did not receive the intentional touch therapy were part of the control group. Parents were recruited from two self-help parent bereavement groups using purposive and snowball sampling 
methods. No details were provided of the purposive sampling method. All enrolled mothers had lost a child during the last 6 to 60 months. Tragers' Psychophysical Integration approach includes "calm rhythmic rocking and light shaking" (p. 345) of the participant's body to release the pain and memory of the traumatic event. ${ }^{26}$ The intervention group sessions were delivered for 6 to 8 weeks by trained and certified Trager practitioners over a 14-week timeframe. It was unclear if mothers in the control group received any other forms of therapy. The study reported statistically significant effect of the touch therapy on three grief related symptoms including despair, depersonalization, and somatization.

\section{Expressive arts therapy.}

Webb-Ferebee's ${ }^{27}$ dissertation study used a pre-test/post-test quasi-experimental design without a control group. This study evaluated the impact of an expressive arts therapy intervention on a function of 10 bereaved family members (i.e., 7 mothers, 2 grandmothers, and 1 grandfather) ${ }^{27}$ Family members had lost a child within the last 2 to 36 months. Enrolled family members attended a weekend camp and participated in a variety of expressive arts activities in a combination of group formats (i.e., multi-family groups; parents' groups; developmental age groups for children; total children's groups; individual family groups; a mothers' group; \& a fathers' group). Various forms of art such as painting, sculpting, music, dance, and acting were included. Standardized measures including the Family Environment Scale, Beck's Anxiety and Depression Inventories and the Behavioral Symptoms Index were administered pre- and postintervention. ${ }^{27}$ No significant differences were found in the pre- and post-test scores between the two groups. The responses of the participating family members did suggest a trend in some improvement in family function scores.

\section{Multi-modal interventions}

Three studies used a combination of interventions to offer bereavement care for parents. Darbyshire $^{32}$ used an interpretive phenomenology method to assess the bereaved parents' perception and experience with a telephone bereavement-care intervention. A nurse from the oncology team was 
assigned to the child's family shortly after the child's death. The assigned nurse called the bereaved parents at relevant times over 13 months. No details of the telephone conversation were provided, but the intent was to stay connected to the bereaved parents during the first 13 months after the child's death. In addition, this nurse attended the child's funeral, sent personalized birthday cards and offered other resources, including connecting the family with professionals or support groups as needed. Parents shared they felt supported and appreciated the continued relationship with a healthcare team member who cared for their child. This opportunity to connect with a known health care team member assisted parents in the process of meaning-making after their child's death.

Two articles described the use of three complementary components: a support package, peer support contact, and health care provider contact. The support package included information on mourning, grief, coping strategies, crisis care, as well as poems and stories about the loss of a child. The peer support contact occurred via a telephone call about a week after the child's death and continued as per the bereaved individual's need. The healthcare providers that were a part of the child's primary care team also contacted the bereaved parent at two to six weeks after the child's death. Contact was either via telephone or in-person based on the parent's preference. The healthcare providers were given written information about grief and grief related topics that they could include in their conversations with the parents, in addition to any topic the parent wanted to discuss. For both studies, parents were randomized based on the hospital that provided care to the child. Parents who had a child in a hospital that provided the intervention were in the intervention group and hospitals that provided standard care were part of the control group.

Aho et al. ${ }^{31}$ described the implementation of a multi-modal bereavement care intervention for fathers following the death of a child including perinatal deaths. The study used a single measure, posttest design and compared 62 fathers in the intervention group to 41 fathers in the control group. ${ }^{31}$ One standardized instrument (Hogan Grief Reaction Checklist) ${ }^{34}$ was used to measure grief and one study specific instrument was developed by the first author to measure social support. Participants were randomized to either group based on the hospital from which they were recruited. The study reported 
significant differences in personal growth among fathers. Fathers in the intervention group reported more personal growth. In addition, fathers in the intervention group had significantly less blame and anger compared to the control group. Contact with health care personnel and peers was reported as supportive.

Raitio et al. ${ }^{33}$ described the implementation of the multi-modal bereavement care package with bereaved mothers. This study used a single measure in a post-test control-group design that evaluated differences between mothers in the intervention group $(n=83)$ compared to mothers in a control group $(\mathrm{n}=53)$. Among mothers receiving the intervention, the results showed: (a) maternal age and selfperceived health, and the deceased child's age were associated with maternal grief reactions; (b) greater support from health care professionals was associated with stronger personal growth of grieving mothers; and (c) no significant difference in maternal grief reactions was found between the intervention and control group.

\section{B. Intervention Effectiveness and Efficacy.}

Based on the GRADE tool, the nine studies reviewed evidence ratings were: very low- 1; low- 3; and low to moderate -5 . The articles varied in research design and included: two randomized clinical trials, five quasi-experimental, one qualitative, and one case study. Efficacy flaws included the use of studyspecific, author-created, non-validated measurement tools to assess outcomes. ${ }^{31,32,35}$ Several studies had intervention fidelity limitations in that they did not describe protocols for their telephone or support group curriculum. ${ }^{26,28,31-33,35}$ Only two studies included group randomization ${ }^{31,33}$; however, in these studies, randomization to groups was based on the hospital setting where the child died (i.e., two hospitals received the intervention and three were in the control group). The qualitative study was described as an interpretive phenomenology in which participants were interviewed following the implementation of a unit based telephone support program, ${ }^{32}$ but the stated study design did not reflect a phenomenological study.

\section{Theoretical Frameworks.}

Among the nine articles reviewed, only two articles ${ }^{28,30}$ described the use of a theoretical model to guide the design and implementation of a bereavement intervention. Dawson's ${ }^{28}$ support group model was 
developed based on Cognitive-Behavioral Theory (CBT). ${ }^{36}$ Dawson acknowledged that, while grief is a natural state following a loss, CBT has been beneficial in treating depressive and anxiety symptoms, which often co-occur in grief. Additionally, the author cited a study in which some cognitive behavioral strategies, such as meaning making and learning health-protective behaviors, assisted in the adjustment of bereaved widows.

Cacciatore $^{30}$ used the ATTEND model, a mindfulness-based bereavement care model built upon the precept of self-care and compassion, integral for those who work in the emotionally intense fields of social work. The model encompassed the experiences of clients, clinicians, and their therapeutic relationships.

Two studies ${ }^{27,31}$ introduced the history of theories in the literature review section. However, the authors did not describe how they designed and implemented their interventions based on the specific theories introduced. For example, $\mathrm{Aho}^{37}$ discussed how social support is conceptualized by $\mathrm{Kahn}^{38}$ in the literature review, but failed to describe how they designed and implemented their intervention based on Kahn's theory. ${ }^{31}$

In Webb-Ferebee's dissertation study, ${ }^{27}$ the history, process, and evolution of expressive arts therapy were described in the literature review; but it was not clear how this information was applied in the method section. One of the models discussed in this study was Moos ${ }^{39}$ model of grief, indicating that grief happens on many levels including individual, family, and societal levels. Moos ${ }^{39}$ grief model recognizes families as a system and posits that individuals in a family are defined by their interactions with one another in the system. The author, however, did not describe how the intervention was guided by the theory.

\section{The Timing of Intervention}

The timeframe for parent bereavement interventions varied after a death. The earliest delivery of a parent bereavement intervention was prior to the parent(s) leaving the hospital when a support packet of written bereavement materials was provided. ${ }^{31,33}$ Three interventions (33.33\%) occurred exclusively 
within the first year of the child's death. ${ }^{31-33}$ Six interventions $(66.66 \%)$ occurred beyond the first year and up to five years after the child's death. ${ }^{25-30}$

Interventions occurred at varying points after the loss of a child. In the two studies with the earliest points of intervention delivery, mothers ${ }^{33}$ and fathers ${ }^{31}$ were given packets of written bereavement materials prior to leaving the hospital after the death of their child. Additional support was provided in the form of telephone calls and or home visits, both of which were concluded within six weeks of the child's death; and the earliest conclusion of any intervention. ${ }^{31,33}$

Six studies provided bereaved parent interventions beyond the first year of the child's death. ${ }^{25-30}$ The case study examined a mindfulness-based intervention used with a bereaved African American single father beginning 14 months after the loss of his son and continued over a 20 month time period. ${ }^{30}$ In another study, bereaved mothers received touch therapy within 6 to 60 months after their child's death. ${ }^{26}$ Families who attended a weekend therapeutic retreat had lost their child within the last one to five years. ${ }^{29}$ In another study, bereaved parents participated in expressive art therapies at a weekend camp within 2 to 36 months after their child's death. ${ }^{27}$ Heiney et al. included bereaved parents attending a 7 -session support group from 2 to 26 months after their child's' death. ${ }^{25}$ In Darbyshire et al.'s study, a nurse from the child's oncology team attended the funeral and then provided bereavement telephone calls to the family over the following 13 months. ${ }^{32}$ Lastly, in Dawson's study, parents' whose child died between child between three months up to four years participated in a six-week support group intervention. ${ }^{28}$

\section{E. Recruitment and Sample Size.}

Several recruitment concerns were not explicitly addressed in the reviewed parent bereavement intervention studies. Several of these studies recruited participants from pre-existing bereavement groups. Due to being in an existing bereavement intervention, these parents may already be more likely to participate in and possibly benefit from other bereavement interventions. ${ }^{26,28,29,32}$ Additionally, small sample sizes were common among the reviewed studies, with the smallest (non-case study) sample having 5 parent participants ${ }^{25}$ and the largest having 136 parent participants. ${ }^{29}$ Although two studies specifically focused on bereaved fathers, this population was underrepresented. ${ }^{30,31}$ In the nine studies 
reviewed, there were 430 intervention participants, including 150 fathers (35\%), 268 mothers (62\%), and $12(3 \%)$ others (grandparents and children).

Lastly, two studies evaluated parent bereavement support groups offered by the hospital where the deceased child was treated. ${ }^{25,28}$ It was unclear in both of these studies whether the support group was located on the hospital grounds. Some families may find it difficult to return to the hospital, especially soon after the child's death, and this could deter participation.

\section{Discussion}

The most notable finding in this literature review is the paucity of well-established bereavement care interventions for bereaved parents. Due to the limited number of intervention studies, we included all studies that even remotely appeared to be bereavement interventions for bereaved parents. Several flaws were noted in the research designs in the studies reviewed. The GRADE tool considers effect sizes, methodological flaws, and inconsistencies to determine the level of evidence. Since none of the studies we reviewed reported effect sizes, we were only able to evaluate studies based on methodological flaws and inconsistencies. Methodological flaws of the reviewed studies included small sample sizes; sample and methodological heterogeneity (i.e., sample demographics, intervention type, and intervention timing); lack of attention or description of an intervention fidelity process; and lack of any discussion about potential effect of confounding factors on the study outcomes. Concerns about the feasibility and replicability of the reviewed intervention also affected the quality rating of the bereavement interventions in this literature review. All these issues posed threats to the internal/external validity of the studies and intervention efficacy.

Selection bias was evident in most of the reviewed studies. Only two of the reviewed studies used randomization to select participants, ${ }^{31,33}$ one was a case study, ${ }^{30}$ and all other studies' recruitment was through convenience sampling, where parent participants self-selected into the intervention. ${ }^{25,27-29,32,40}$ Recruiting using support group or parents who are members of organization creates a sampling bias as being part of a support group itself can be therapeutic. ${ }^{25}$ 
Recruitment for bereavement research is challenging due to the sensitivity of the topic and vulnerability of the population. ${ }^{41}$ Dawson et. al. ${ }^{28}$ specifically highlighted the high attrition rate and difficulty in recruitment resulting in changing study design. Pediatric providers and institutional review boards are protective of this population due to the vulnerability and sensitivity of the topic creating recruitment challenges, ${ }^{11,41,42}$ which can negatively influence the recruitment of parents to bereavement intervention studies. In an effort to overcome sample size issues, research often is extended to a more heterogeneous population with a wide age group or time since death, which affect the study validity. ${ }^{19,41}$

Few studies reported positive outcomes of the intervention(s). Kempson ${ }^{26}$ reported that intentional touch therapy had a positive effect on despair, depersonalization and somatization. Cacciatore $^{30}$ found the mindfulness intervention decreased trauma responses, anxiety symptoms, and depression symptoms. Participation in a weekend therapeutic retreat resulted in improvement in depression symptoms and positive effect. ${ }^{29}$ Qualitative studies supported prior research narratives that bereaved parents appreciated the support from hospital staff members who knew their child ${ }^{42}$ and had the ability to connect with other bereaved parents. ${ }^{32}$ An evaluation of a hospital-based multi-modal intervention bereavement program found no statistical difference between the intervention and control groups, the reason of which might be due to the short length of time (six months after the loss) when the evaluation was conducted. ${ }^{33}$ Inadequate reporting of study procedures and treatments by investigators limits the replicability of the interventions and thus limits the ability to confirm or refute any reported study findings. ${ }^{22}$

The effective development and implementation of interventions require researchers to integrate theories as the foundation for their interventions. Bartholomew et al. ${ }^{43}$ recommended the appropriate integration of theoretical frameworks to facilitate: (a) identifying problems, (b) explaining the logic of change, (c) selecting appropriate interventions, (d) evaluating relationships among constructs, and (e) reporting findings. In this review, only two studies explicitly illustrated how their bereavement interventions were designed based on theoretical models. ${ }^{28,30}$ Researchers should develop interventions with theoretical foundations and avoid retrospectively overlaying a theory for their interventions. ${ }^{43}$ 


\section{Implications and Recommendations}

Due to the unique nature of grief experiences and the diversity of family systems, the one-size fits all bereavement care approach does not work. This review supports Forte's recommendation that to improve parental bereavement care, the interventions must be targeted to specific populations and tested through randomized-control trials with a focus on specific bereavement outcomes. ${ }^{22}$ Alternatively, one specific intervention may not be suitable for all people, and those who are bereaved might not always need professional support. We support the recommendation of Endo et al. ${ }^{19}$ of doing feasibility and validity studies prior to doing randomized-control trials to avoid expenditure on interventions that are not feasible and/or do not achieve appropriate health outcomes.

The diversity in individual experiences can influence parental grief and bereavement. ${ }^{44}$ Therefore, when designing interventions for bereaved parents, researchers need to take into consideration parents' individual differences and design interventions that can be tailored to individual needs. The Integrative Risk Factor Framework for the Prediction of Bereavement Outcome developed using the Dual Process Model of Coping with Bereavement and cognitive stress and coping models, highlights the need for nuanced and individualized care for bereaved individuals. ${ }^{44,45}$ The framework incorporates five elements including: (a) the nature of the stressor; (b) interpersonal resources; (c) intrapersonal resources; (d) appraisal and coping processes; and (e) outcomes. ${ }^{44}$ Each of these elements has multiple variables that can impact an individual's grief process and subsequently, their physical, emotional, psychological, cognitive and social outcomes. Using this framework, interventions for bereaved parents should be offered based on the individual's identified needs, rather than one type of intervention applied broadly to the population.

Additionally, the Integrative Palliative Care $\mathrm{Model}^{46}$ highlights the need to integrate bereavement care during palliative care. The model recommends the use of a pediatric palliative care liaison that works with the family during the child's palliative phase to create a collaborative bereavement care plan for the family. ${ }^{46}$ This collaborative plan approach can be integrated for all families experiencing a child's death due to chronic illnesses or even in case of sudden death. This model can be a true representation of holistic family care-centered approach in which we care for the sick child and the caregiving parents. 
Using an integrative palliative care model with an array of multi-modal bereavement care interventions can be effective in addressing the individualized bereavement needs and have the potential to improve bereaved parents' health outcomes.

Bereaved parents have higher morbidity and mortality rates when compared to non-bereaved parents. ${ }^{10,48,49}$ Therefore, bereavement care interventions must measure health-related outcomes including

physical, psychological, social, and spiritual health. ${ }^{11}$ Additionally, budgetary restrictions for bereavement care services play a role in implementing economical and standardized bereavement care interventions. ${ }^{46,47}$ Bereavement care must be an integral element of pediatric palliative care that focuses on parental health promotion and disease prevention with a goal to improve bereaved parents' health outcomes. In order to justify budgetary needs, a paradigm shift must occur in which bereavement care is viewed not as an extension of pediatric palliative care, but rather an important element of palliative care. ${ }^{47}$

\section{Conclusions}

The methodological flaws in the examined intervention studies included: lack of using a control group, non-randomization, use of non-standardized measures, as well as heterogeneous and small sample sizes. These flaws hinder the evaluation of the efficacy and generalizability of the interventions ${ }^{22,41}$ Therefore, the studies in this literature review are not adequate for recommendations of effective bereavement care interventions. Additionally, only one study was published within the last five years, which highlights the dearth in intervention studies for bereaved parents. ${ }^{33}$ In summary, the state of the current science on published interventions for bereaved parents is very poor and much work needs to be done to effectively address the needs of bereaved parents, including both their physical and emotional health needs. 


\section{References}

1. Christ GH, Bonano G, Malkinson R, Rubin S. Appendix E: Bereavement Experiences After the Death of a Child. In: Board on Health Sciences P, Institute of M, Committee on Palliative and End-of-Life Care for Children and Their F, eds. When Children Die: Improving Palliative and End-of-Life Care for Children and Their Families.: National Academies Press; 2017:553-579.

2. Rosenberg AR, Baker KS, Syrjala K, Wolfe J. Systematic review of psychosocial morbidities among bereaved parents of children with cancer. Pediatric Blood \& Cancer. 2012;58(4):503-512.

3. Song J, Floyd FJ, Seltzer MM, Greenberg JS, Hong J. Long-term effects of child death on parents' health-related quality of life: A dyadic analysis. Family Relations: An Interdisciplinary Journal of Applied Family Studies. 2010;59(3):269-282.

4. Albuquerque S, Pereira M, Narciso I. Couple's relationship after the death of a child: A systematic review. Journal of Child and Family Studies. 2016;25(1):30-53.

5. $\quad$ Under-five mortality. World Health Organization;2017.

6. Kochanek KD, Murphy, S.L., Xu, J., Tejada-Vera, B. National Vital Statistics Reports. 2016;65(4).

7. Steele AC, Kaal J, Thompson AL, et al. Bereaved parents and siblings offer advice to health care providers and researchers. J Pediatr Hematol Oncol. 2013;35(4):253-259.

8. Stevenson M, Achille M, Liben S, et al. Understanding How Bereaved Parents Cope With Their Grief to Inform the Services Provided to Them. Qualitative Health Research. 2017;27(5):649664.

9. Barrera M, Alam R, D'Agostino NM, Nicholas DB, Schneiderman G. Parental Perceptions of Siblings' Grieving After a Childhood Cancer Death: A Longitudinal Study. Death Studies. 2013;37(1):25-46.

10. Brooten D, Youngblut JM, Caicedo C, del Moral T, Cantwell GP, Totapally B. Parents' Acute Illnesses, Hospitalizations, and Medication Changes During the Difficult First Year After Infant or Child NICU/PICU Death. American Journal of Hospice and Palliative Medicine. 2018;35(1):75-82.

11. Dias N, Brandon D, Haase JE, Tanabe P. Bereaved Parents' Health Status During the First 6 Months After Their Child's Death. The American journal of hospice \& palliative care. 2018;35(6):829.

12. Youngblut JM, Brooten D, Cantwell GP, del Moral T, Totapally B. Parent health and functioning 13 months after infant or child NICU/PICU death. Pediatrics. 2013;132(5):e1295-e1301.

13. Cacciatore J, Killian M, Harper M. Adverse outcomes in bereaved mothers: The importance of household income and education. SSM - Population Health. 2016;2:117-122.

14. Barrera M, O'Connor K, D'Agostino NM, et al. Early parental adjustment and bereavement after childhood cancer death. Death Studies. 2009;33(6):497-520.

15. Shreffler KM, Hill PW, Cacciatore J. Exploring the Increased Odds of Divorce Following Miscarriage or Stillbirth. Journal of Divorce \& Remarriage. 2012;53(2):91-107.

16. Donovan LA, Wakefield CE, Russell V, Cohn RJ. Hospital-based bereavement services following the death of a child: A mixed study review. Palliative Medicine. 2015;29(3):193-210.

17. Meert KL, Schim SM, Briller SH. Parental bereavement needs in the pediatric intensive care unit: review of available measures. J Palliat Med. 2011;14(8):951-964.

18. Harvey S, Snowdon C, Elbourne D. Effectiveness of bereavement interventions in neonatal intensive care: a review of the evidence. Semin Fetal Neonatal Med. 2008;13(5):341-356.

19. Endo K, Yonemoto N, Yamada M. Interventions for bereaved parents following a child's death: A systematic review. Palliative Medicine. 2015;29(7):590-604.

20. Rowa-Dewar N. Do interventions make a difference to bereaved parents? A systematic review of controlled studies. Int J Palliat Nurs. 2002;8(9):452-457. 
21. Garstang J, Griffiths F, Sidebotham P. What do bereaved parents want from professionals after the sudden death of their child: A systematic review of the literature. BMC Pediatrics. 2014;14(1):269-269.

22. Forte AL, Hill M, Pazder R, Feudtner C. Bereavement care interventions: a systematic review. BMC Palliat Care. 2004;3(1):3.

23. Andrews J, Guyatt G, Oxman AD, et al. GRADE guidelines: 14. Going from evidence to recommendations: the significance and presentation of recommendations. Journal of Clinical Epidemiology. 2013;66(7):719-725.

24. Balshem H, Helfand M, Schünemann HJ, et al. GRADE guidelines: 3. Rating the quality of evidence. J Clin Epidemiol. 2011;64(4):401-406.

25. Heiney SP, Ruffin J, Goon-Johnson K. The effects of a support group on selected psychosocial outcomes of bereaved parents whose child died from cancer. J Pediatr Oncol Nurs. 1995;12(2):51-58; discussion 59-61.

26. Kempson DA. Effects of intentional touch on complicated grief of bereaved mothers. Omega: Journal of Death and Dying. 2000;42(4):341-353.

27. Webb-Ferebee KL. Expressive arts therapy with bereaved families, ProQuest Dissertations Publishing; 2001.

28. Dawson WW. Symptomatology of bereaved parents who have lost a child to cancer: A 6-week group therapy intervention, ProQuest Dissertations Publishing U6 - ctx_ver=Z39.882004\&ctx_enc=info\%3Aofi\%2Fenc\%3AUTF-

$8 \& \mathrm{rfr}$ id $=$ info $\% 3 \mathrm{Asid} \% 2 \mathrm{Fsummon}$. serialssolutions.com\&rft_val_fmt $=$ info $\% 3 \mathrm{Aofi} \% 2 \mathrm{Ffmt} \% 3 \mathrm{Ak}$ ev\%3Amtx\%3Adissertation\&rft.genre=dissertation\&rft.title $=$ Symptomatology + of + bereaved + par ents+who+have+lost $+\mathrm{a}+$ child + to + cancer $\% 3 \mathrm{~A}+\mathrm{A}+6-$

week+group+therapy+intervention\&rft.DBID $=\mathrm{H} 8 \mathrm{~S} \% 3 \mathrm{BG} 20 \% 3 \mathrm{~B} 0 \mathrm{BH} \% 3 \mathrm{BEU} \% 3 \mathrm{~B} 0 \mathrm{GP} \% 3 \mathrm{BC} 1$ 6\%3B054\&rft.PQPubID=18750\&rft.au=Dawson\%2C+Wendy+Wyone\&rft.date=2003-0101\&rft.pub=ProQuest+Dissertations+Publishing\&rft.externalDocID=765395091\&paramdict=enUS U7 - Dissertation; 2003.

29. Brown W. Weekend therapeutic retreats for bereaved parents: Effects on depression, quality of life, and perceptions of social support, ProQuest Dissertations Publishing; 2009.

30. Cacciatore J, Thieleman K, Osborn J, Orlowski K. Of the soul and suffering: Mindfulness-based interventions and bereavement. Clinical Social Work Journal. 2014;42(3):269-281.

31. Aho AL, Tarkka MT, Astedt-Kurki P, Sorvari L, Kaunonen M. Evaluating a bereavement followup intervention for grieving fathers and their experiences of support after the death of a child--a pilot study. Death Stud. 2011;35(10):879-904.

32. Darbyshire P, Cleghorn A, Downes M, et al. Supporting bereaved parents: A phenomenological study of a telephone intervention programme in a paediatric oncology unit. Journal of Clinical Nursing. 2013;22(3-4):540-548.

33. Raitio K, Kaunonen M, Aho AL. Evaluating a bereavement follow-up intervention for grieving mothers after the death of a child. Scandinavian Journal of Caring Sciences. 2015;29(3):510-520.

34. Hogan NS, Greenfield Db Fau - Schmidt LA, Schmidt LA. Development and validation of the Hogan Grief Reaction Checklist. (0748-1187 (Print)).

35. Wiener LS. Telephone support groups for HIV-positive mothers whose children have died of AIDS. Social Work. 1998;43(3):279-285.

36. Craske MG, American Psychological A. Cognitive-behavioral therapy. Second ed. Washington, DC: American Psychological Association; 2017.

37. Aho AL, Astedt-Kurki P, Tarkka MT, Kaunonen M. Development and implementation of a bereavement follow-up intervention for grieving fathers: an action research. $J$ Clin Nurs. 2011;20(3-4):408-419.

38. Kahn RL. Aging and social support. Bolder, CO: Westview Press; 1979.

39. Moos NL. An integrative model of grief. Death Studies. 1995;19(4):337-364. 
40. Kempson DA. Effects of Intentional Touch on Complicated Grief of Bereaved Mothers. OMEGA - Journal of Death and Dying. 2001;42(4):341-353.

41. Akard TF, Gilmer MJ, Miller K, et al. Factors affecting recruitment and participation of bereaved parents and siblings in grief research. Progress in Palliative Care. 2014;22(2):75-79.

42. Dias N, Docherty S, Brandon D. Parental bereavement: Looking beyond grief. Death Studies. 2017;41(5):318-327.

43. Bartholomew LK, Mullen PD. Five roles for using theory and evidence in the design and testing of behavior change interventions. J Public Health Dent. 2011;71 Suppl 1:S20-33.

44. Stroebe MS, Folkman S, Hansson RO, Schut H. The prediction of bereavement outcome: development of an integrative risk factor framework. Soc Sci Med. 2006;63(9):2440-2451 .

45. Stroebe M, Schut H. The dual process model of coping with bereavement: rationale and description. Death Studies. 1999;23(3):197-224.

46. Kobler K, Limbo R. Making a case: creating a perinatal palliative care service using a perinatal bereavement program model. J Perinat Neonatal Nurs. 2011;25(1):32-41; quiz 42-33.

47. Morris SE, Dole OR, Joselow M, Duncan J, Renaud K, Branowicki P. The Development of a Hospital-Wide Bereavement Program: Ensuring Bereavement Care for All Families of Pediatric Patients. J Pediatr Health Care. 2016.

48. Morris SE, Block SD. Adding Value to Palliative Care Services: The Development of an Institutional Bereavement Program. J Palliat Med. 2015.

49. Dias NA-Ohoo, Brandon D, Haase JE, Tanabe P. Bereaved Parents' Health Status During the First 6 Months After Their Child's Death. (1938-2715 (Electronic)).

50. Li J, Precht DH, Mortensen PB, Olsen J. Mortality in parents after death of a child in Denmark: A nationwide follow-up study. The Lancet. 2003;361(9355):363-367. 